\title{
Perceptions, Determinants and Residential Satisfaction from Urban Open Spaces
}

\author{
Evgenia Anastasiou1, Stella Manika² \\ ${ }^{1}$ Laboratory of Demographic and Social Analyses, Department of Planning and Regional Development, University of Thessaly, \\ Volos, Greece \\ ${ }^{2}$ Laboratory of Urban Morphology, Department of Planning and Regional Development, University of Thessaly, \\ Volos, Greece \\ Email: evanastasiou@uth.gr, smanika@uth.gr
}

How to cite this paper: Anastasiou, E., \& Manika, S. (2020). Perceptions, Determinants and Residential Satisfaction from Urban Open Spaces. Open Journal of Social Sciences, $8,1-18$.

https://doi.org/10.4236/jss.2020.86001

Received: May 3, 2020

Accepted: May 30, 2020

Published: June 2, 2020

Copyright (c) 2020 by author(s) and Scientific Research Publishing Inc. This work is licensed under the Creative Commons Attribution International License (CC BY 4.0).

http://creativecommons.org/licenses/by/4.0/

cc (i) Open Access

\begin{abstract}
Quality of life as a cross-disciplinary term is explored by the sciences of urban planning and design, geography, and social sciences. The present paper: 1) investigates the factors of satisfaction of visitors to the urban open space; 2) highlights complex patterns of residents' satisfaction from the contribution of a bioclimatic renovation project in this area. For the needs of the present, field research was conducted on the residents of a medium-sized Greek city. The urban open space chosen presents a multi-functional character, consists pole of attraction for visitors based on the variety of its uses, and encompasses a special cultural and historical identity. The methodological approach is initially based on a multi-criteria analysis (Factor Analysis) to capture the characteristics that shape the disadvantages and dynamics of urban open space in order to obtain the factors of residential satisfaction. Based on the evaluation of the satisfaction factors (Principal Components), a hierarchical classification was applied, exploring the main patterns of residential satisfaction regarding the contribution of the bioclimatic regeneration project. The findings show that residents' satisfaction with urban open space is a function of five factors: the overall operation of the open space, the quality of leisure facilities, the contribution of the bioclimatic design of large scale project, the suitability of infrastructure for children and respect for the cultural identity of the place. The satisfaction based on the acceptance of the project of bioclimatic regeneration showed that only one in four residents is satisfied with the overall contribution of the project, while the vast majority of residents are nonetheless dissatisfied. Finally, there emerge six profiles of residents, in terms of their degree of satisfaction compared to the other interpretive variables.
\end{abstract}

\section{Keywords}

Residential Satisfaction, Urban Open Space, Bioclimatic Design, Factor 
Analysis, Hierarchical Clustering

\section{Introduction}

Urban open spaces are the driving force behind the city's structure and viability as such spaces strengthen the feeling of community (Francis et al., 2012; Cao \& Wang, 2016) and the sense of neighborliness in the presence of historical and cultural monuments, in the demarcation and "thriving" of landscapes, in the increase of land value in broader urban units, and finally, in the level of investment attraction. At the same time, green open spaces are intertwined with regulation of temperature and humidity, the quality of ambient air, the reduction of noise, and the absorption and storage of carbon dioxide. Depending on their structure and functionality, urban open spaces contribute greatly to the quality of life of citizens. On the one hand, this interdependence stems from the traits of place, and on the other hand, on the traits of its inhabitants, as well as the relationship between those two important factors.

The study of residential satisfaction factors in an open urban space is particularly crucial and complex. It is therefore important to be able in any case to determine the factors that contribute, to a greater or lesser extent, to the satisfaction of residents or visitors. The more objective, complete, and quantitative this analysis is, the closer we are to the performance of the concept of residential satisfaction in these areas. At the same time, these spaces are examined either as a whole or as more fragmentary and departmental, based on their individual characteristics. These characteristics may correspond to sections of old infrastructure or new infrastructure, such as a bioclimatic regeneration project. This paper, drawing on the existing bibliography, proceeds to identify those characteristics that affect the residential satisfaction of open urban space, as an empirical study, in a medium-sized Greek city. While then it proceeds to identify the complex patterns that develop between the characteristics of these spaces and the satisfaction of the visitors.

\section{Literature Reviews}

The impact of urban open spaces is reflected in the physical (Cohen et al., 2007; Tzoulas et al., 2007) and mental health of individuals in a variety of different ways, as those areas often become spaces of recreation, communication or sports, for various age and social groups, especially when these spaces are at a walking distance from people's homes (Schipperijn et al., 2017). Visiting an urban open space, for example, can bring someone relaxation (Kaplan, 1985) as well as reduce their anxiety levels (Chiesura, 2004). Such positive feelings are reinforced when these spaces are of high-function or when a significant part of these areas is covered by vegetation.

That is to say, "green spaces" within the urban fabric seem to reduce the sense 
of insecurity or fear of citizens (Kuo \& Sullivan, 2001). However, many visitors to green urban open spaces often experience diametrically opposite views. The question that arises thus concerns what their responsibility is in terms of their personal sense of safety and security, and what are the responsibilities of municipal authorities (Rickard, Scherer, \& Newman, 2011; Hanisah et al., 2016). Conversely, open green spaces are often sufficiently neglected; that is, limited management and planning, inadequate cleaning or lighting as well as frequent commercialization are the most important reasons for the degradation of urban public open spaces.

Confronting these problems, increasing the satisfaction of visitors to an urban open space through empirical research can both help enhance its urban role and increase the well-being and quality of life of residents. According to C.C.M. Adriaanse (Adriaanse, 2007), empirical studies on the satisfaction of residents can be distinguished into two categories. The first category takes resident satisfaction as a predictive factor of their behavior, such as decisions to move to different areas and places for example, and is based on the relationship between the needs or desires of the individual and the state of their surroundings. The second category values resident satisfaction so as to examine the quality of their space, their surrounding environment, neighborhood, or the broader urban unit/district (Adriaanse, 2007). In each category, it is important to identify the determining factors of the degree of satisfaction of the residents or visitors of a place. These factors can include the specific characteristics of the space that make it potentially attractive or the specific characteristics of people that determine their actions and decisions.

The social and economic profile of individuals and the connections made from past cultural environments and situations are factors that determine one's appreciation of urban open spaces (Vemuri et al., 2011; Diener, Oishi, \& Tay, 2018) in terms of the decision to visit those spaces or not (Petrosillo et al., 2007), as well the potential frequency of visits/participation in those areas (Eng \& Niininen, 2005). Information about the profile of visitors to an area can thus assist the most efficient design, efficient management (Lepesteur et al., 2008), and the future of this space (Wang et al., 2015). This process forms the method of adaptive learning and involves the relationships that form between people and their social - ecological environment (Davidson-Hunt \& Berkes, 2003). This method, while it can refer to either to residents or tourists to the areas under study, will nevertheless prioritize permanent residents of areas, as tourists or visitors have a more -spatially and temporally-malleable view of their surroundings.

The multidimensional scale of a residential satisfaction model was initiated by Canter and Rees (1982) focusing on the satisfaction of the inhabitants for the assessment of the residential environment (Adriaanse, 2007) and treating the results as key for urban planning. Furthermore, a plethora of current researches focused on the question of residential satisfaction has been carried out. These researches present a full spectrum of variables, methods, and approaches. Buys 
and Miller (2012) predict residential satisfaction with an emphasis on inner urban higher-density environments. Furthermore, Wu et al. (2020) interrelate the usage of a park with residential satisfaction. Ngesan et al. (2013) show the role of the design of urban public parks in the positive residential perception with an emphasis on variables related to nighttime leisure. Francis et al. (2012) give prominence to the relation between high-quality public spaces and the enhancement of the sense of community. Wood et al. (2008) explore the effects of the built environment on social capital and feelings of safety. In parallel, Lovejoy et al. (2010) examine the characteristics associated with higher levels of neighborhood satisfaction among residents of traditional or suburban neighborhoods.

Thus far we can conclude that a variety of criteria are usually used to form the scale of the assessment of urban space. What is interesting in this case is that the criteria are likely to be defined and understood differently both by the residents themselves and by urban planners (Hofmann et al., 2012).

At any rate, however, the first criterion that is to be considered is the presence and availability of green spaces (Hitchings, 2013). It is evident in this case, then, that social and cultural criteria are of lesser importance in this scale (Ives et al., 2017). However, it should be emphasized that social and cultural factors define the identity of a region and establish a person's connection to it (Chan, Peters, \& Marafa, 2015). The satisfaction of a visitor to the urban space is also influenced by criteria that are determined by the availability and design of the infrastructure areas or their variety and by the characteristics of the landscape surrounding it (Real et al., 2000; Hofmann et al., 2012). Furthermore, the rising "consumption of public goods" expresses the demand of residents for public goods ( $\mathrm{Lu}, 2020$ ). As the modern resident spends more and more time in digital and virtual spaces, it is imperative to explore the characteristics that will make urban open spaces more attractive, thus increasing resident satisfaction and bringing open spaces back to the social spotlight (Gifford, 2014).

\section{Data}

International literature suggests a wide range of interpretative variables regarding the residents' satisfaction of multi-functional urban open areas (Table 1), while the science of environmental psychology itself tends to present a variety of research changes in recent years in terms of the satisfaction of visitors to a public urban space (Giuliani \& Scopelliti, 2009).

The area under study is the city of Larisa and more specifically the historical city center. The population in the field survey consists of the residents of Larisa (144,651 in total). Larisa is a typical example of a Greek urban morphological structure with a limited number of open spaces, yet at the same time, Larisa is a city where policymakers step up their efforts to generate more sustainable environmental forms to the city through bioclimatic regeneration projects (implementation of the Sustainable Urban Mobility Plan). The spatial unit that formed the core of this study consists of the historic center of the city (Lofos Frouriou, 
Table 1. Factors for the satisfaction of visitors to urban public open spaces.

\begin{tabular}{|c|c|c|}
\hline Component & Variable & Relevant Literature \\
\hline \multirow{6}{*}{ Infrastructure } & Existence of infrastructure & (Buys \& Miller, 2012) \\
\hline & Accessibility of infrastructure & $\begin{array}{l}\text { (Lee \& Hong, 2013; Rioux et al., 2016; Abass \& Tucker, 2018; Fasihi \& } \\
\text { Parizadi, 2020; Manika, 2018) }\end{array}$ \\
\hline & Existence of children's infrastructure & (Wu et al., 2020) \\
\hline & Quality of children's infrastructure & (Van Herzele \& Wiedemann, 2003; Tzoulas \& James, 2010) \\
\hline & Appropriateness of the infrastructure & (Eng \& Niininen, 2005) \\
\hline & Parking spaces & (Schipperijn et al., 2013; Hasani, Sakieh \& Khammar, 2017) \\
\hline \multirow{2}{*}{ Maintenance } & Infrastructure maintenance & (Van Herzele \& Wiedemann, 2003) \\
\hline & Vegetation conservation & (Lo \& Jim, 2010) \\
\hline \multirow{4}{*}{ Recreation } & Green spaces & (Nicol \& Blake, 2000; Chiesura, 2004; Hofmann et al., 2012; Paul \& Nagendra, 2017) \\
\hline & Population concentration & (Aragonés et al., 2017) \\
\hline & Recreation and entertainment & (Yu et al., 2018) \\
\hline & Food services & (Oğuz \& Çakcì, 2010) \\
\hline \multirow{4}{*}{ Entertainment } & Events & (Chan, Peters \& Marafa, 2015) \\
\hline & Cultural identity & (Chan, Peters, \& Marafa, 2015; Nuzzaci, 2020) \\
\hline & Information of the citizens & (Wong, 2009) \\
\hline & Entertainment activities at night & (Ngesan et al., 2013) \\
\hline \multirow{3}{*}{ Safety } & Night lighting & (Kuo \& Sullivan, 2001) \\
\hline & Sense of security & (Hur \& Morrow-Jones, 2008; Albouy, Christensen, \& Sarmiento-Barbieri, 2018) \\
\hline & Vandalism in public places & (Albouy, Christensen, \& Sar-miento-Barbieri, 2018) \\
\hline \multirow{3}{*}{$\begin{array}{l}\text { Bioclimatic } \\
\text { regeneration project }\end{array}$} & Aesthetic improvement & (Nicol \& Blake, 2000; Real, Arce, \& Manuel Sabucedo, 2000) \\
\hline & Improvement of microclimate & (Georgi \& Dimitriou, 2010; Mahmoud, 2011) \\
\hline & Increase of visitors & (Wong, 2009) \\
\hline
\end{tabular}

Source: same compilation.

Agios Achilleos, Ancient Theatre) and the bioclimatic regeneration project which was completed in 2016, in form of a policy of emanating better environmental conditions and a new aesthetic identity in this area, which was met with a multitude of different reactions from citizens.

\section{Methods}

In order to investigate the factors that influence the satisfaction of residents in urban public spaces, we designed a tool for measuring satisfaction, based on international literature.

The closed-type questionnaire consists of three sections:

1) The first section sets out demographic and social data, such as gender, age, marital status, number of children, and level of education.

2) The second section contains information on the specific time period and 
frequency of visits to the area under study, as well as the main reason for visiting.

3) Finally, the third section consists of questions aimed at highlighting the satisfaction factors of the residents and are related to their perceptions of the area's facilities, maintenance, recreation and entertainment, the feeling of safety, and the contribution of bioclimatic regeneration.

The data originating from the first and the second section are nominal, while the third section's data are interval, measured with 5-point Likert scales.

Data were collected by random sampling techniques and the overall sample consists of 530 people. The sampling lasted two months (May and June 2019) and took place in the location under study. The results are reliable with a confidence level of $95 \%$ and a margin of error of $4 \%$. After the data collection, they were coded and entered into a database in order to draw statistical inferences.

The methodological approach is based on methods of descriptive and exploratory statistical analysis (Factor Analysis, Hierarchical clustering). The descriptive results were presented in the form of percentage breakdowns and average values and a comparison was made between the different characteristics/traits of the sample. In prioritizing the importance of the results, independence tests were carried out with non-parametric tests.

In order to identify the factors influencing the visitors' satisfaction of urban open areas, Factor Analysis was conducted in 22 initial variables. Through a logical correlation of data and concepts, analytical methods allowed the information of the large amount of data resulting from the on-site survey to be condensed. This method is an extremely useful tool for analyzing complex phenomena that cannot be measured directly, especially when they involve attitudes, perceptions, and human behaviors (Gliem \& Gliem, 2003). This tool involves a limited number of new hyper-variables (Thurstone, 1947), which ensures the simplification and generalization of the dataset.

The basic requirement for using the factor analysis is to satisfy the criterion of the ratio of the initial variables in relation to the number of observations in the sample. In the case of the present survey and according to the international literature, the ratio of 10:1 (Garson, 2008) (530 observations, 22 variables) is satisfied. The Kayser Meyer Olkin index is particularly high (0.877) (Kaiser, 1974) and attests to the high consistency between the data and thus their suitability for analysis. The contribution of each variable in the model is at least satisfactory $(>0.4)$ (Tabachnick \& Fidell, 2007). The investigation of the factors was carried out by the analysis of Principal Components and the method of rotation of the axes was conducted with Varimax. Five principal components (77\% dimension reduction) emerged after consideration of the eigenvalues $(\lambda>1)$ (Guttman, $1954)$, and the percentage of the total variation of the initial variables reflected by the new ones.

In continuation, a cluster analysis was then performed based on the new interpretive factors of satisfaction resulting from the Principal Component Analysis. The purpose of the cluster analysis application is to investigate the impact of 
factors on residents' satisfaction. Consequently, in the first phase, it was examined whether distinct profiles of residents with high homogeneity were observed.

This methodology utilizes agglomerative hierarchical analysis in order to group data. In cumulative methods, each object is initially considered as a group. Then, the most comparable objects are selected and merged, creating a new group. From the resulting groups, the most comparable are selected and merged. The process is repeated until all objects are included in a single group. The hierarchical cluster analysis method used is Ward's method that reduces the sort of variance in clusters. This is a fairly effective way of producing compact clusters as it maximizes homogeneity within them (Pham \& Afify, 2007). The metric distance used is the squared Euclidean distance between the two centroids of the merged clusters.

Then through exploratory analysis, we created the residents' profiles. The analysis showed at the first level three broad groups of residents based on their satisfaction with the bioclimatic regeneration project. At the second level, each category is developed in individual profiles, based on age classification and other interpretive variables. The profiles are characterized by internal homogeneity, while among the other profiles a high heterogeneity is identified.

\section{Results}

The research sample consists of 530 people of whom women have relative numerical superiority (55.3\%) (Table 2). The highest numbers of both men surveyed $(28.7 \%)$ and women $(27.9 \%)$ are found in the $15-24$ age group, while as the age limit slightly increases, the percentage of survey participants slightly decreases.

The bivariate analysis does not, however, show a significant statistical difference between the age groups in terms of the gender of respondents $(p>0.05)$. On the other hand, there is a statistically significant difference in the level of education between men and women $(p<0.05)$, with differences focusing on two levels of education. That is, with regards to in primary school in which women have higher rates $(7.8 \%$ vs. $3.4 \%)$ and with regards to higher education where men have higher rates (39.2\% vs $34.9 \%)$. Regarding marital status, there is no significant statistical correlation between $(p>0.05)$ between single or married men and women.

The reasons for visiting the urban open space under consideration vary according to demographic characteristics (Table 3), with the sole exception of gender-related preferences, where there are no statistically significant differences between men and women. On the contrary, age is an interpretative factor of the reasons people visit the areas in the field study.

Young people (15 - 24 years old) choose to visit this area for walking, relaxation, and recreation (42.2\%). A fairly high rate of visitation of this area for the same reason comes from people from ages 25 - 34 (20\%), while the percentage 
Table 2. Sample demographic profile.

\begin{tabular}{|c|c|c|c|c|c|c|c|}
\hline & Men & $\%$ & Women & $\%$ & Total & $\%$ & \multirow{2}{*}{$\begin{array}{c}p \text {-value } \\
\text { Chi-square }\end{array}$} \\
\hline Sample & 237 & 44.7 & 293 & 55.3 & 530 & $100 \%$ & \\
\hline \multicolumn{7}{|c|}{ Age } & \multirow{6}{*}{0.863} \\
\hline $15-24$ & 68 & $28.7 \%$ & 80 & $27.3 \%$ & 148 & $27.9 \%$ & \\
\hline $25-34$ & 61 & $25.7 \%$ & 79 & $27.0 \%$ & 140 & $26.4 \%$ & \\
\hline $35-44$ & 46 & $19.4 \%$ & 54 & $18.4 \%$ & 100 & $18.9 \%$ & \\
\hline $45-54$ & 32 & $13.5 \%$ & 48 & $16.4 \%$ & 80 & $15.1 \%$ & \\
\hline$>55$ & 30 & $12.7 \%$ & 32 & $10.9 \%$ & 62 & $11.7 \%$ & \\
\hline \multicolumn{7}{|c|}{ Education level } & \multirow{5}{*}{0.048} \\
\hline Primary school & 8 & $3.4 \%$ & 23 & $7.8 \%$ & 31 & $5.8 \%$ & \\
\hline High School & 83 & $35.0 \%$ & 106 & $36.2 \%$ & 189 & $35.7 \%$ & \\
\hline Bachelor's degree & 93 & $39.2 \%$ & 92 & $31.4 \%$ & 185 & $34.9 \%$ & \\
\hline \multirow[t]{2}{*}{ Master/Phd } & 53 & $22.4 \%$ & 72 & $24.6 \%$ & 125 & $23.6 \%$ & \\
\hline & \multicolumn{4}{|c|}{ Marital status } & & & \multirow{4}{*}{0.103} \\
\hline Single & 126 & $53.2 \%$ & 148 & $50.5 \%$ & 274 & $51.7 \%$ & \\
\hline Married & 108 & $45.6 \%$ & 132 & $45.1 \%$ & 240 & $45.3 \%$ & \\
\hline Other & 3 & $1.3 \%$ & 13 & $4.4 \%$ & 16 & $3.0 \%$ & \\
\hline
\end{tabular}

Table 3. Profile of the sample based on the reason for the visit.

\begin{tabular}{|c|c|c|c|c|c|c|c|c|c|c|c|c|}
\hline \multirow{3}{*}{ Characteristics } & \multirow{3}{*}{ Categories } & \multicolumn{8}{|c|}{ Reasons for visiting the urban open space } & & & \multirow{3}{*}{$p$-value } \\
\hline & & \multicolumn{2}{|c|}{ Walking/Recreation } & \multicolumn{2}{|c|}{$\begin{array}{l}\text { Visit the } \\
\text { Metropolitan Church }\end{array}$} & \multicolumn{2}{|c|}{ Food services } & \multicolumn{2}{|c|}{ Cultural activities } & \multicolumn{2}{|c|}{ Total } & \\
\hline & & $\mathrm{f}$ & $\%$ & $\mathrm{f}$ & $\%$ & $\mathrm{f}$ & $\%$ & $\mathrm{f}$ & $\%$ & $\mathrm{f}$ & $\%$ & \\
\hline \multirow{3}{*}{ Gender } & Men & 78 & $42.2 \%$ & 14 & $32.6 \%$ & 139 & $47.8 \%$ & 6 & $54.5 \%$ & 237 & $44.7 \%$ & \\
\hline & Total & 185 & $100.0 \%$ & 43 & $100.0 \%$ & 291 & $100.0 \%$ & 11 & $100.0 \%$ & 530 & $100.0 \%$ & \\
\hline & $15-24$ & 78 & $42.2 \%$ & 2 & $4.7 \%$ & 67 & $23.0 \%$ & 1 & $9.1 \%$ & 148 & $27.9 \%$ & \\
\hline \multirow{6}{*}{ Age } & $25-34$ & 37 & $20.0 \%$ & 2 & $4.7 \%$ & 98 & $33.7 \%$ & 3 & $27.3 \%$ & 140 & $26.4 \%$ & \\
\hline & $35-44$ & 27 & $14.6 \%$ & 8 & $18.6 \%$ & 64 & $22.0 \%$ & 1 & $9.1 \%$ & 100 & $18.9 \%$ & 0.000 \\
\hline & $45-54$ & 27 & $14.6 \%$ & 10 & $23.3 \%$ & 42 & $14.4 \%$ & 1 & $9.1 \%$ & 80 & $15.1 \%$ & \\
\hline & $>55$ & 16 & $8.6 \%$ & 21 & $48.8 \%$ & 20 & $6.9 \%$ & 5 & $45.5 \%$ & 62 & $11.7 \%$ & \\
\hline & Total & 185 & $100.0 \%$ & 43 & $100.0 \%$ & 291 & $100.0 \%$ & 11 & $100.0 \%$ & 530 & $100.0 \%$ & \\
\hline & Single & 109 & $58.9 \%$ & 4 & $9.3 \%$ & 157 & $54.0 \%$ & 4 & $36.4 \%$ & 274 & $51.7 \%$ & \\
\hline \multirow{3}{*}{ Marital status } & Married & 71 & $38.4 \%$ & 35 & $81.4 \%$ & 128 & $44.0 \%$ & 6 & $54.5 \%$ & 240 & $45.3 \%$ & \\
\hline & Other & 5 & $2.7 \%$ & 4 & $9.3 \%$ & 6 & $2.1 \%$ & 1 & $9.1 \%$ & 16 & $3.0 \%$ & 0.000 \\
\hline & Total & 185 & $100.0 \%$ & 43 & $100.0 \%$ & 291 & $100.0 \%$ & 11 & $100.0 \%$ & 530 & $100.0 \%$ & \\
\hline \multirow{4}{*}{ Number of children } & 0 & 111 & $60.0 \%$ & 6 & $14.0 \%$ & 189 & $64.9 \%$ & 5 & $45.5 \%$ & 311 & $58.7 \%$ & \\
\hline & 1 & 24 & $13.0 \%$ & 3 & $7.0 \%$ & 30 & $10.3 \%$ & 2 & $18.2 \%$ & 59 & $11.1 \%$ & \\
\hline & 2 & 34 & $18.4 \%$ & 27 & $62.8 \%$ & 54 & $18.6 \%$ & 3 & $27.3 \%$ & 118 & $22.3 \%$ & 0.000 \\
\hline & $>3$ & 16 & $8.6 \%$ & 7 & $16.3 \%$ & 18 & $6.2 \%$ & 1 & $9.1 \%$ & 42 & $7.9 \%$ & \\
\hline
\end{tabular}


decreases markedly in the ages over $35(14.6 \%)$. Reasons such as walking or recreation do not seem to be attracting people over 55 years old to the areas under study (8.6\%), contrary to the intention to visit the Metropolitan Church (48.4\%) or participating in local cultural events (45.5\%). Visit Churches begin to have a greater resonance in the middle-aged people. More specifically, $20 \%$ of people who visit those specific areas for religious reasons consist of the age group of 45 - 54 years old. In terms of food services, on the other hand, there seems to be a smoother distribution between age groups. The highest percentage in terms of such services is found in the age group 25 - 34 (33.7\%) since different types of services are recreational spaces for many people in this group. Fairly high rates are also seen in the groups 15 - 24 (23\%) and 35 - 44 (22\%), while those over the age of 50 do not consider the food services a significant reason for visiting the area.

Finally, in terms of participation in cultural events, people over 55 (45.4\%) show the highest rates of interest, as well as people aged 25 - 34 (27.3\%). On the other hand, the other age groups have a reduced interest in cultural events (9.1\%) and participate in cultural activities. Marital status also plays an important role in the reasons behind visiting the areas under study. Single people use those spaces for walking and recreation (58.9\%), while married people visit those spaces for religious observation and participation in cultural events (81.4\%). Food services as a reason for visiting the spaces in question seem to concern both married people (44\%) as well as unmarried participants (54\%), who slightly outnumber married participants. The number of children is another statistically important component in interpreting the reasons for the visits. The majority of people attracted to the spaces in question for recreation and food services have no children (60\% and $64.9 \%$ ), while $30 \%$ of people who visit those spaces for walking have at least 1 or 2 children (79.1\%). Finally, cultural activities are important for the groups with no children (45.5\%), but also to participants with 2 children $(27.3 \%)$ and these percentages may be related to the nature of the activity in which they participate.

Concluding with the descriptive statistics there are observed statistically significant differences among demographic characteristics in the reasons for visiting the public open space.

\subsection{Determinants for Residential Satisfaction}

The exploratory factor analysis reduced the volume of data, and from 22 variables it identified 5 principal components that interpret $63.9 \%$ of the total variability (Table 4). In order of decreasing importance of the total variation, the five components that determine the satisfaction of the inhabitants of Larisa in the areas under study are 1) Smooth and integrated operation of the urban open spaces 2) Level of leisure benefits 3) Contribution of bioclimatic regeneration projects 4) Existence of infrastructure for children 5) Respect for cultural identity. 
Table 4. Rotated component matrix.

\begin{tabular}{|c|c|c|c|c|c|c|}
\hline & \multicolumn{6}{|c|}{ Principal Components } \\
\hline & Communalities $\left(\mathrm{H}^{2}\right)$ & 1 & 2 & 3 & 4 & 5 \\
\hline Infrastructure maintenance & 0.697 & 0.749 & & & & \\
\hline Parking spaces & 0.619 & 0.721 & & & & \\
\hline Sense of security & 0.510 & 0.668 & & & & \\
\hline Information of the citizens & 0.612 & 0.630 & & & & \\
\hline Vegetation conservation & 0.579 & 0.628 & & & & \\
\hline Entertainment activities at night & 0.517 & 0.569 & & & & \\
\hline Events & 0.507 & 0.507 & & & & \\
\hline Recreation and entertainment & 0.700 & & 0.788 & & & \\
\hline Food services & 0.640 & & 0.761 & & & \\
\hline Population concentration & 0.522 & & 0.493 & & & \\
\hline Green spaces & 0.473 & & 0.417 & & & \\
\hline Increase of visitors & 0.800 & & & 0.871 & & \\
\hline Aesthetic improvement & 0.819 & & & 0.865 & & \\
\hline Improvement of microclimate & 0.772 & & & 0.834 & & \\
\hline Existence of children's infrastructure & 0.805 & & & & 0.866 & \\
\hline Quality of children's infrastructure & 0.781 & & & & 0.841 & \\
\hline Appropriateness of the infrastructure & 0.551 & & & & 0.538 & \\
\hline Cultural identity & 0.719 & & & & & 0.811 \\
\hline Vandalism & 0.608 & & & & & 0.707 \\
\hline$\%$ of total Variance & & 33.9 & 9.5 & 8.1 & 6.8 & 5.3 \\
\hline
\end{tabular}

1st component: Smooth and integrated operation of urban open space $(33.9 \%$ of total variation)

The first composite indicator refers to the general feeling of satisfaction felt by the residents from the use of the infrastructure of the urban open spaces. Seven variables are involved and positively correlated in the component composition. Data indicates that people prioritize the fact that infrastructure must be adequately maintained, and the level of vegetation conservation should be maintained at an acceptable level. At the same time, the question of adequate parking spaces is important, while the general sense of security felt by anyone who goes to the spaces under study also plays a decisive role. The interpretation of the component is complemented by the use of the space for both event planning and evening activities.

2nd component: Level of leisure benefits (9.5\%)

The second composite index incorporates the variables relating to beneficial and rejuvenating recreation elements. It consists of four individual dimensions, while the variables that make up it correlate positively. The composite indicator initially highlights the need to use urban open space for recreational purposes. 
Consequently, there is also a need for leisure services and related venues. To be considered beneficial, the activity also requires an acceptable number of users and/or visitors to the area so that there is no over-concentration of population, thus ultimately losing its utilitarian value. The last variable that complements the interpretation of the composite index is the existence of vegetation and green spaces, which would benefit the population because of the positive effects of nature.

3rd component: Contribution of bioclimatic upgrade projects (8.1\%)

The third indicator incorporates the advantages offered by bioclimatic upgrade projects in the field. The three variables involved in the synthesis of the third component have high factor loadings while at the same time correlate positively. As a result, bioclimatic upgrade projects add value when the traffic of the site increases at the same time as its aesthetic improvement and upgrade. Finally, the improvement of microclimate is an important factor due to the placement of sunblinds and the application of the principles of geothermal energy.

4th component: Existence of children's infrastructure (6.8\%)

The fourth composite indicator clearly illustrates the parents' view of the existence, quality, and appropriateness of the infrastructure of the area in question for children. The three variables that make up the composite index have high factor loadings and are positively correlated. It is essentially about the search for a comfortable, friendly, and safe place, where every parent can bring their child, and offer them a welcoming place for socialization. The focus of the component concerns the use of urban open space through appropriate activities, giving a sense of quality, safety, and protection.

5th component: Respect for cultural identity (5.3\%)

The fifth component interprets the smallest percentage of the total variation, but it is nevertheless of major importance. It reflects the inhabitants' feeling and appreciation of the cultural identity of the area. It combines two initial variables that are positively correlated: knowledge of the history of the area and any possible vandalism observed in the area. The degree of influence of these characteristics constitutes the level of respect for cultural heritage.

The deconstruction of residents' perceptions in order to capture their satisfaction for a phenomenon is an extremely complex procedure. The five principal components emerged from the exploratory analysis highlight the main factors affecting residential satisfaction from urban open spaces. What is crucial is the convergence of residents' views to the general sense of the operation of the urban space. In addition to the smooth operation of open space, it seems that residents are looking for a place that offers a high sense of leisure, and children's infrastructure. The contribution of bioclimatic upgrade projects has also a positive impact on satisfaction. Finally, both the knowledge and the appreciation of space's historic identity have a positive effect on residential satisfaction.

\subsection{Residents' Profiles}

As far as the bioclimatic regeneration project is concerned, the question is 
whether the project was finally accepted by the public. The results of the analysis show that only one in four residents of Larissa $(25 \%)$ is satisfied with the overall contribution of the project, while the vast majority (64.1\%) residents are nonetheless dissatisfied (Table 5). The hierarchical classification highlighted three major groups based on the satisfaction of the residents with the contribution of the bioclimatic regeneration project: 1) Satisfied 2) Dissatisfied 3) No difference. The groups in which the residents are classified include subgroups since in addition to the basic criterion of satisfaction with the project, they present different profiles in terms of their degree of satisfaction in relation to the other interpretive variables.

Satisfied Residents. Satisfied residents with the bioclimatic regeneration project represent $25 \%$ of the population. Among the satisfied residents are found 2 profiles of residents with different characteristics.

The first group (a1) concerns $20 \%$ of the population and the dominant age group is the younger generation aged $15-24$. The profile of the residents is focused on the feeling of the very high contribution of the projects both in the area of the urban park and in the wider area. At the same time, the residents have the perception that the cultural value of the urban park is more widely accepted, as they themselves seem to know the history of the area quite well and at the same time do not distinguish between vandalism in the area. The profile of the individuals in this group is generally characterized by a positive attitude towards the overall image of the urban park. In general, the residents are satisfied with the operation of the park and consider that it meets the expectations for recreation. The only downside is that there is no infrastructure suitable for children.

The profile of the second group (a2) of satisfied residents shows significant differences compared to the first. It represents a very low percentage of the population (4.9\%), which is clearly satisfied with both the bioclimatic regeneration project and the variety and quality of infrastructure related to children's activities.

Table 5. Profile of residents based on satisfaction with the bioclimatic regeneration project.

\begin{tabular}{|c|c|c|c|c|c|c|c|c|}
\hline & Group & Residents (\%) & Dominant Age & $\begin{array}{c}\text { Overall } \\
\text { operation } \\
\text { of the park }\end{array}$ & $\begin{array}{c}\text { Level of leisure } \\
\text { benefits }\end{array}$ & $\begin{array}{l}\text { Contribution of } \\
\text { bioclimatic } \\
\text { upgrade projects }\end{array}$ & $\begin{array}{l}\text { Existence of } \\
\text { children's } \\
\text { infrastructure }\end{array}$ & $\begin{array}{c}\text { Respect for } \\
\text { cultural identity }\end{array}$ \\
\hline \multirow[b]{2}{*}{ Satisfied } & a1 & 20.0 & $15-24$ & + & + & ++ & - & + \\
\hline & a2 & 4.9 & $\begin{array}{l}15-24, \\
25-34\end{array}$ & -- & -- & ++ & ++ & - \\
\hline \multirow{4}{*}{ Dissatisfied } & b1 & 27.5 & $>45$ & - & - & - & - & ++ \\
\hline & b2 & 4.5 & $\begin{array}{l}15-24 \\
25-34\end{array}$ & -- & - & - & -- & -- \\
\hline & b3 & 18.7 & $25-34$ & + & ++ & -- & + & ○ \\
\hline & b4 & 13.4 & $\begin{array}{l}15-24 \\
25-34\end{array}$ & ++ & -- & -- & + & - \\
\hline No difference & $\mathrm{cl}$ & 10.9 & $15-24$ & 0 & + & 0 & ++ & -- \\
\hline
\end{tabular}

++ high satisfaction, + satisfaction, $\circ$ no satisfaction, - dissatisfaction, -- high dissatisfaction. 
The dominant age groups that make up the profile of the category are $15-24$ and 25 - 34. Unlike the previous group, the residents do not consider the importance of the cultural identity of the area to be perceived, while they state that they are particularly dissatisfied with both the quality of the leisure offered by the urban park and its overall operation.

Dissatisfied Residents. The majority of Larissa residents (64.1\%) express their dissatisfaction with the overall contribution of the bioclimatic regeneration project to the hill of the fortress. However, depending on the age structure and satisfaction with the other interpretive components, dissatisfied residents are categorized into four distinct groups.

The profile of the first group (b1) represents $27.5 \%$ of the population, while the dominant age groups are over 45 . People belonging to this group have a more general negative feeling both about the renovation project and about the overall picture of the urban park. They believe that space is not being used as much as possible, it is unable to offer high-quality recreation and the infrastructure for children is limited. However, the inhabitants seem to know and appreciate the cultural value of the location, a fact that may be explained by the historical knowledge that accompanies the older age groups.

The second group (b2) is dominated by a reaction climate and is characterized by a completely negative attitude. It concerns only a small percentage of young people under the age of 35 (4.5\%) with a significant lack of knowledge of the history of the area, who find the park insufficient in terms of its overall image and operation and especially in terms of lack of infrastructure and facilities for the children. The recreation component also receives a negative sign in satisfaction, but with less intensity than the previous components.

The third group refers to a significant percentage of dissatisfied residents (18.7\%) with a predominant age of 25 - 34, who express the highest levels of dissatisfaction with the bioclimatic regeneration project. Beyond that, however, they are particularly pleased with space's leisure benefits and believe that space maintains a fairly acceptable level of facilities and infrastructure for children's activities. At the same time, their perception of the overall image of the park is positive.

The final profile of dissatisfied residents represents $13.4 \%$ of the population, with the under-34s predominant. Despite the group's strong dissatisfaction with the bioclimatic regeneration project, there is a high level of satisfaction with the recruitment of the park's facilities for both children and the proper functioning of the space as a whole. On the contrary, it expresses strong dissatisfaction with the leisure provided, while its sensitivity to cultural heritage is diminished.

No noticeable difference: In addition to satisfied and dissatisfied residents, there is a third category ( $\mathrm{c} 1$ ) according to which the bioclimatic regeneration project did not offer any noticeable positive difference but at the same time did not have any negative effects on the urban park. The group incorporates $10.9 \%$ of the population and the predominant age is young people aged $15-24$. Due to 
the young age, there is a negative sign in the respect they show for cultural heritage, but on the contrary, the members of this group express their satisfaction with the high quality of recreation facilities and the infrastructure concerning the amount of space for children.

Our findings confirm the main points of the bibliographic review, while at the same time opening new paths in the measurement of the residential satisfaction of urban open spaces, given that an important parameter of the results is related to the determination of the satisfaction derived from the bioclimatic regeneration project. These projects are current choices of municipalities, as a function of their expected and self-evident characteristics as part of municipalities' efforts to become "smarter". However, the bibliographic and research review related to the residential satisfaction of visitors is limited.

\section{Conclusion}

The question of satisfaction from a city's public open space has been studied quite a bit, but most quantitative surveys focus on limited features of urban space. More specifically, preexisting studies typically focus on green spaces in the city, their form or maintenance, and much less other important characteristics of the urban space, such as its cultural or social profile. The present study aimed to address this gap by combining a holistic approach to urban space with the demographic and social profile of its visitors and the characteristics of their visit, in terms of specific time period and frequency.

The study area chosen is the historical center of a medium-sized Greek city and combines green spaces, places of increased cultural importance, religious sites, recreation, entertainment, and a network of bike paths and pedestrian streets. At the same time, a bioclimatic upgrade project was carried out in this area, and although it was partially accepted by the residents for its environmental contribution, it received several negative comments due to its aesthetics.

The reasons for visiting the area in question vary considerably between the age groups, the marital status, and the number of children of the participants. According to the multivariate analysis conducted for this study, the factors contributing to the satisfaction of visitors to this urban open space, in order of decreasing importance are 1) the overall picture of the space, 2) the quality of the leisure services, 3) the contribution of bioclimatic regeneration projects, 4) the variety and suitability of the infrastructure for children and 5) respect for the cultural identity of the area. Finally, the analysis confirms poor residential satisfaction in relation to bioclimatic regeneration projects, while there emerge four distinct profiles of dissatisfied residents with heterogeneity in the factors affecting satisfaction.

The application of this methodological framework for the quantitative approach of satisfaction that the visitor draws from an urban open space can be used by policymakers in order to identify the characteristics that make this area more attractive and improve the inhabitants' quality of life. 


\section{Conflicts of Interest}

The authors declare no conflicts of interest regarding the publication of this paper.

\section{References}

Abass, Z. I., \& Tucker, R. (2018). Residential Satisfaction in Low-Density Australian Suburbs: The Impact of Social and Physical Context on Neighborhood Contentment. Journal of Environmental Psychology, 56, 36-45. https://doi.org/10.1016/j.jenvp.2018.02.005

Adriaanse, C. C. M. (2007). Measuring Residential Satisfaction: A Residential Environmental Satisfaction Scale (RESS). Journal of Housing and the Built Environment, 22, 287-304. https://doi.org/10.1007/s10901-007-9082-9

Albouy, D., Christensen, P., \& Sarmiento-Barbieri, I. (2018). Unlocking Amenities: Estimating Public_Good Complementarity. https://doi.org/10.3386/w25107 https://www.nber.org/papers/w25107.pdf

Aragonés, J. I., Amérigo, M., \& Pérez-López, R. (2017). Residential Satisfaction and Quality of Life (pp. 311-328). Cham: Springer.

https://doi.org/10.1007/978-3-319-31416-7_17

Buys, L., \& Miller, E. (2012). Residential Satisfaction in Inner Urban Higher-Density Brisbane, Australia: Role of Dwelling Design, Neighborhood and Neighbors. Journal of Environmental Planning and Management, 55, 319-338.

https://doi.org/10.1080/09640568.2011.597592

Canter, D., \& Rees, K. (1982). A Multivariate Model of Housing Satisfaction. International Review of Applied Psychology, 31, 185-208. https://doi.org/10.1111/j.1464-0597.1982.tb00087.x

Cao, X., \& Wang, D. (2016). Environmental Correlates of Residential Satisfaction: An Exploration of Mismatched Neighborhood Characteristics in the Twin Cities. Landscape and Urban Planning, 150, 26-35. https://doi.org/10.1016/j.landurbplan.2016.02.007

Chan, C. S., Peters, M., \& Marafa, L. M. (2015). Public Parks in City Branding: Perceptions of Visitors vis-à-vis Residents in Hong Kong. Urban Forestry and Urban Greening, 14, 1157-1165. https://doi.org/10.1016/j.ufug.2015.10.016

Chiesura, A. (2004). The Role of Urban Parks for the Sustainable City. Landscape and Urban Planning, 68, 129-138. https://doi.org/10.1016/j.landurbplan.2003.08.003

Cohen, D. A., McKenzie, T. L., Sehgal, A., Williamson, S., Golinelli, D., \& Lurie, N. (2007). Contribution of Public Parks to Physical Activity. American Journal of Public Health, 97, 509-514. https://doi.org/10.2105/AJPH.2005.072447

Davidson-Hunt, I., \& Berkes, F. (2003). Learning as You Journey: Anishinaabe Perception of Social-Ecological Environments and Adaptive Learning. Conservation Ecology, 8, 5. http://www.consecol.org/vol8/iss1/art5 https://doi.org/10.5751/ES-00587-080105

Diener, E., Oishi, S., \& Tay, L. (2018). Advances in Subjective Well-Being Research. Nature Human Behaviour, 2, 253-260. https://doi.org/10.1038/s41562-018-0307-6

Eng, T. Y., \& Niininen, O. (2005). An Integrative Approach to Diagnosing Service Quality of Public Parks. Journal of Services Marketing, 19, 70-80. https://doi.org/10.1108/08876040510591385

Fasihi, H., \& Parizadi, T. (2020). Analysis of Spatial Equity and Access to Urban Parks in Ilam, Iran. Journal of Environmental Management, 260, Article ID: 110122. 
https://doi.org/10.1016/j.jenvman.2020.110122

Francis, J., Giles-Corti, B., Wood, L., \& Knuiman, M. (2012). Creating Sense of Community: The Role of Public Space. Journal of Environmental Psychology, 32, 401-409. https://doi.org/10.1016/j.jenvp.2012.07.002

Garson, D. G. (2008). Factor Analysis: Statnotes.

Georgi, J. N., \& Dimitriou, D. (2010). The Contribution of Urban Green Spaces to the Improvement of Environment in Cities: Case Study of Chania, Greece. Building and Environment, 45, 1401-1414. https://doi.org/10.1016/j.buildenv.2009.12.003

Gifford, R. (2014). Environmental Psychology Matters. Annual Review of Psychology, 65, 541-579. https://doi.org/10.1146/annurev-psych-010213-115048

Giuliani, M. V., \& Scopelliti, M. (2009). Empirical Research in Environmental Psychology: Past, Present, and Future. Journal of Environmental Psychology, 29, 375-386.

https://doi.org/10.1016/j.jenvp.2008.11.008

Gliem, J. A., \& Gliem, R. R. (2003). Calculating, Interpreting, and Reporting Cronbach Alpha Reliability Coefficient for Likert-Type Scales, Midwest Research to Practice Conference in Adult, Continuing, and Community Education. Columbus, $\mathrm{OH}$ : The Ohio State University.

Guttman, L. (1954). Some Necessary Conditions for Common-Factor Analysis. Psychometrika, 19, 149-161. https://doi.org/10.1007/BF02289162

Hanisah, N., Hashim, M., Syed, S. K., Thani, O., Jamaludin, M. A., \& Yatim, M. (2016). A Perceptual Study on the Influence of Vegetation Design towards Women's Safety in Public Park. Procedia-Social and Behavioral Sciences, 234, 280-288.

https://doi.org/10.1016/j.sbspro.2016.10.244

Hasani, M., Sakieh, Y., \& Khammar, S. (2017). Measuring Satisfaction: Analyzing the Relationships between Sociocultural Variables and Functionality of Urban Recreational Parks. Environment, Development and Sustainability, 19, 2577-2594.

https://doi.org/10.1007/s10668-016-9856-x

Hitchings, R. (2013). Studying the Preoccupations That Prevent People from Going into Green Space. Landscape and Urban Planning, 118, 98-102. https://doi.org/10.1016/j.landurbplan.2012.09.006

Hofmann, M., Westermann, J. R., Kowarik, I., \& Van der Meer, E. (2012). Perceptions of Parks and Urban Derelict Land by Landscape Planners and Residents. Urban Forestry and Urban Greening, 11, 303-312. https://doi.org/10.1016/j.ufug.2012.04.001

Hur, M., \& Morrow-Jones, H. (2008). Factors That Influence Residents' Satisfaction with Neighborhoods. Environment and Behavior, 40, 619-635. https://doi.org/10.1177/0013916507307483

Ives, C. D., Oke, C., Hehir, A., Gordon, A., Wang, Y., \& Bekessy, S. A. (2017). Capturing Residents' Values for Urban Green Space: Mapping, Analysis and Guidance for Practice. Landscape and Urban Planning, 161, 32-43.

https://doi.org/10.1016/j.landurbplan.2016.12.010

Kaiser, H. F. (1974). An Index of Factorial Simplicity. Psychometrica, 39, 31-36. https://doi.org/10.1007/BF02291575

Kaplan, R. (1985). The Analysis of Perception via Preference: A Strategy for Studying How the Environment Is Experienced. Landscape Planning, 12, 161-176.

https://doi.org/10.1016/0304-3924(85)90058-9

Kuo, F. E., \& Sullivan, W. C. (2001). Environment and Crime in the Inner City. Environment and Behavior, 33, 343-367. https://doi.org/10.1177/0013916501333002

Lee, G., \& Hong, I. (2013). Measuring Spatial Accessibility in the Context of Spatial Dis- 
parity between Demand and Supply of Urban Park Service. Landscape and Urban Planning, 119, 85-90. https://doi.org/10.1016/j.landurbplan.2013.07.001

Lepesteur, M., Wegner, A., Moore, S. A., \& McComb, A. (2008). Importance of Public Information and Perception for Managing Recreational Activities in the Peel-Harvey Estuary, Western Australia. Journal of Environmental Management, 87, 389-395. https://doi.org/10.1016/j.jenvman.2007.01.026

Lo, A. Y., \& Jim, C. Y. (2010). Willingness of Residents to Pay and Motives for Conservation of Urban Green Spaces in the Compact City of Hong Kong. Urban Forestry and Urban Greening, 9, 113-120. https://doi.org/10.1016/j.ufug.2010.01.001

Lovejoy, K., Handy, S., \& Mokhtarian, P. (2010). Neighborhood Satisfaction in Suburban versus Traditional Environments: An Evaluation of Contributing Characteristics in Eight California Neighborhoods. Landscape and Urban Planning, 97, 37-48.

https://doi.org/10.1016/j.landurbplan.2010.04.010

Lu, L. (2020). Review of Western Research on Demand Recognition of Public Product. Open Journal of Social Sciences, 8, 167-176. https://doi.org/10.4236/jss.2020.84012

Mahmoud, A. H. A. (2011). Analysis of the Microclimatic and Human Comfort Conditions in an Urban Park in Hot and Arid Regions. Building and Environment, 46, 2641-2656. https://doi.org/10.1016/j.buildenv.2011.06.025

Manika, S. (2018). Economic Crisis, Shrinking Cities and Urban Regeneration Policies. Thessaly: University of Thessaly.

Ngesan, M. R., Karim, H. A., Zubir, S. S., \& Ahmad, P. (2013). Urban Community Perception on Nighttime Leisure Activities in Improving Public Park Design. Procedia-Social and Behavioral Sciences, 105, 619-631. https://doi.org/10.1016/j.sbspro.2013.11.065

Nicol, C., \& Blake, R. (2000). Classification and Use of Open Space in the Context of Increasing Urban Capacity. Planning Practice and Research, 15, 193-210. https://doi.org/10.1080/713691902

Nuzzaci, A. (2020). The Right of Children to Use Cultural Heritage as a Cultural Right. Open Journal of Social Sciences, 8, 574-599. https://doi.org/10.4236/jss.2020.84042

Oğuz, D., \& Çakcİ, I. (2010). Changes in Leisure and Recreational Preferences: A Case Study of Ankara. Scientific Research and Essays, 5, 721-729.

Paul, S., \& Nagendra, H. (2017). Factors Influencing Perceptions and Use of Urban Nature: Surveys of Park Visitors in Delhi. Land, 6, 27. https://doi.org/10.3390/land6020027

Petrosillo, I., Zurlini, G., Corlianò, M. E., Zaccarelli, N., \& Dadamo, M. (2007). Tourist Perception of Recreational Environment and Management in a Marine Protected Area. Landscape and Urban Planning, 79, 29-37. https://doi.org/10.1016/j.landurbplan.2006.02.017

Pham, D. T., \& Afify, A. A. (2007). Clustering Techniques and Their Applications in Engineering. Mechanical Engineering Science, 221, 1445-1459. https://doi.org/10.1243/09544062JMES508

Real, E., Arce, C., \& Manuel Sabucedo, J. (2000). Classification of Landscapes Using Quantitative and Categorical Data, and Prediction of Their Scenic Beauty in North and Western Spain. Journal of Environmental Psychology, 20, 355-373. https://doi.org/10.1006/jevp.2000.0184

Rickard, L. N., Scherer, C. W., \& Newman, S. B. (2011). Exploring Attribution of Responsibility for Visitor Safety in a US National Park. Health, Risk \& Society, 13, 527-545. https://doi.org/10.1080/13698575.2011.613983 
Rioux, L., Werner, C. M., Mokounkolo, R., \& Brown, B. B. (2016). Walking in Two French Neighborhoods: A Study of How Park Numbers and Locations Relate to Everyday Walking. Journal of Environmental Psychology, 48, 169-184. https://doi.org/10.1016/j.jenvp.2016.10.003

Schipperijn, J., Bentsen, P., Troelsen, J., Toftager, M., \& Stigsdotter, U. K. (2013). Associations between Physical Activity and Characteristics of Urban Green Space. Urban Forestry and Urban Greening, 12, 109-116. https://doi.org/10.1016/j.ufug.2012.12.002

Schipperijn, J., Cerin, E., Adams, M. A., Reis, R., Smith, G., Cain, K., Christiansen, L. B., Dyck, D. van, Gidlow, C., Frank, L. D., Mitáš, J., Pratt, M., Salvo, D., Schofield, G., \& Sallis, J. F. (2017). Access to Parks and Physical Activity: An Eight Country Comparison. Urban Forestry and Urban Greening, 27, 253-263. https://doi.org/10.1016/j.ufug.2017.08.010

Tabachnick, B. G., \& Fidell, L. S. (2007). Using Multivariate Statistics (5th ed.). Boston, MA: Pearson Allyn \& Bacon.

Thurstone, L. L. (1947). Multiple Factor Analysis: A Development and Expansion of Vectors of the Mind. Chicago, IL: University of Chicago.

Tzoulas, K., \& James, P. (2010). Peoples' Use of, and Concerns about, Green Space Networks: A Case Study of Birchwood, Warrington New Town, UK. Urban Forestry and Urban Greening, 9, 121-128. https://doi.org/10.1016/j.ufug.2009.12.001

Tzoulas, K., Korpela, K., Venn, S., Yli-Pelkonen, V., Kaźmierczak, A., Niemela, J., \& James, P. (2007). Promoting Ecosystem and Human Health in Urban Areas Using Green Infrastructure: A Literature Review. Landscape and Urban Planning, 81, 167-178. https://doi.org/10.1016/j.landurbplan.2007.02.001

Van Herzele, A., \& Wiedemann, T. (2003). A Monitoring Tool for the Provision of Accessible and Attractive Urban Green Spaces. Landscape and Urban Planning, 63, 109-126. https://doi.org/10.1016/S0169-2046(02)00192-5

Vemuri, A. W., Grove, J., Wilson, M. A., \& Burch, W. R. (2011). A Tale of Two Scales: Evaluating the Relationship among Life Satisfaction, Social Capital, Income, and the Natural Environment at Individual and Neighborhood Levels in Metropolitan Baltimore. Environment and Behavior, 43, 3-25. https://doi.org/10.1177/0013916509338551

Wang, D., Brown, G., Liu, Y., \& Mateo-Babiano, I. (2015). A Comparison of Perceived and Geographic Access to Predict Urban Park Use. Cities, 42, 85-96. https://doi.org/10.1016/j.cities.2014.10.003

Wong, K. K. (2009). Urban Park Visiting Habits and Leisure Activities of Residents in Hong Kong, China. Managing Leisure, 14, 125-140. https://doi.org/10.1080/13606710902752653

Wood, L. et al. (2008). The Anatomy of the Safe and Social Suburb: An Exploratory Study of the Built Environment, Social Capital and Residents' Perceptions of Safety. Health and Place, 14, 15-31. https://doi.org/10.1016/j.healthplace.2007.04.004

Wu, W., Dong, G., Sun, Y., \& Yun, Y. (2020). Contextualized Effects of Park Access and Usage on Residential Satisfaction: A Spatial Approach. Land Use Policy, 94, Article ID: 104532. https://doi.org/10.1016/j.landusepol.2020.104532

Yu, B., Che, S., Xie, C., \& Tian, S. (2018). Understanding Shanghai Residents' Perception of Leisure Impact and Experience Satisfaction of Urban Community Parks: An Integrated and IPA Method. Sustainability, 10, 1-17. https://doi.org/10.3390/su10041067 